\title{
High performance removal of sulfamethoxazole using large specific area of biochar derived from corncob xylose residue
}

\author{
Yinxue $\mathrm{Li}^{1} \cdot$ Hongru Shang ${ }^{1} \cdot{\text { Yongna } \mathrm{CaO}^{1} \cdot \text { Chunhui Yang }}^{1,2} \cdot$ Yujie Feng $^{2} \cdot$ Yanling $\mathrm{Yu}^{1}$
}

Received: 23 June 2021 / Accepted: 19 October 2021

(c) The Author(s) 2022

\begin{abstract}
To remove antibiotics from waste water, an alkali active porous biochar, $850 \mathrm{BC}$, was prepared from corncob xylose residue. In preparation, $\mathrm{NaOH}$ dipping was used for silicon removal and $\mathrm{KOH}$ activation was operated at $850^{\circ} \mathrm{C}$. Further characterization containing BET, SEM, and FTIR were confirmed. 850BC possessed a huge specific surface area of $3043 \mathrm{~m}^{2} \cdot \mathrm{g}^{-1}$, developed pore structure and abundant oxygen functional groups. The adsorption performance of sulfamethoxazole on 850BC was quick and efficient, and the adsorption capacity reached $1429 \mathrm{mg} \cdot \mathrm{g}^{-1}$, which was significantly higher than other adsorbents reported previously. While pseudo-second-order kinetic model and Langmuir model could better describe the adsorption, chemisorption dominated the SMX adsorption onto $850 \mathrm{BC}$. In virtue of pore-filling and $\pi-\pi$ interaction as major mechanism, a large surface area and rich oxygen-containing functional groups led to an excellent adsorption performance. Thus, this preparation method provided a biochar-based adsorbent with enhanced specific surface for efficient removal of antibiotic pollutants.
\end{abstract}

\section{Graphical Abstract}

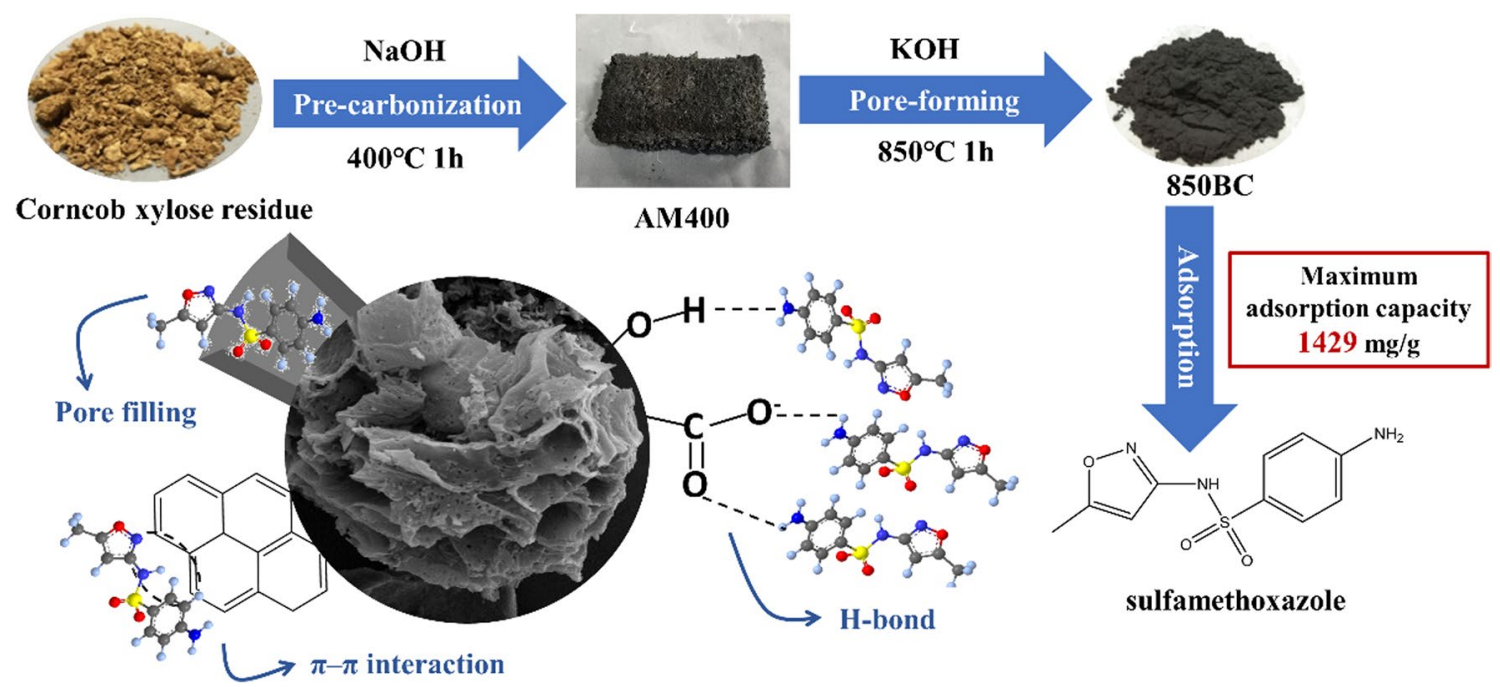

\section{Highlights}

- Corncob xylose residue biochar was modified by $\mathrm{KOH}$ with huge surface area.

Yanling Yu

yuyanling@hit.edu.cn
- Biochar product possessed excellent absorption quantity of SMX of $1429 \mathrm{mg} \cdot \mathrm{g}^{-1}$.

- The SMX on biochar adsorption was mainly attributed to pore filling effect, $\pi-\pi$ interactions, and hydrogen bonding.

Extended author information available on the last page of the article 
Keywords Corncob xylose residue $\cdot$ Biochar $\cdot$ Sulfamethoxazole $\cdot$ Adsorption behavior $\cdot$ Adsorption mechanism

\section{Introduction}

Antibiotics, the most commonly used antibacterial drugs in the world, are ubiquitous and continuously discharged into environments due to extensive consumption (Grenni et al. 2017). The long half-lives lead to pseudo persistence, accumulation, high bioactivity, and biodegradation resistance of most antibiotics, once they enter the environment (Ben et al. 2020; Han et al. 2020). Thus, antibiotic residues are likely to pose a potential toxic threat to ecosystem from long-term exposure at low concentrations (Isidori et al. 2005), and may lead resistant pathogens to infect humans and animals (Ngigi et al. 2019). Antibiotic pollution has become an emerging concern and important class of pollutants in water environment, and residues of antibiotics have been detected in many different matrices accordingly (Chen et al. 2020). The antibiotic concentration had been measured up to $15 \mu \mathrm{g} \cdot \mathrm{L}^{-1}$ in the Americas, a higher concentration over $50 \mu \mathrm{g} \cdot \mathrm{L}^{-1}$ was reported from African, and the concentration over $450 \mu \mathrm{g} \cdot \mathrm{L}^{-1}$ had been detected in Asian-pacific countries (Danner et al. 2019). Yang et al. (2013) detected 17-304 ng. $\mathrm{L}^{-1}$ ciprofloxacin, 6.9-65 $\mathrm{ng} \cdot \mathrm{L}^{-1}$ sulfamethoxazole (SMX), and 0.3-8.8 ng. $\mathrm{L}^{-1}$ erythromycin in the Pearl River Delta in China. De Souza (2006) found the microbial colonies with the resistance of both heavy metal and antibiotics were isolated in Antarctic waters due to long-term exposure to low antibiotic concentrations and heavy metals. The major source of antibiotic pollution in aquatic environment is the discharge from wastewater treatment plants (WWTPs), including pharmaceutical wastewater, hospital sewage, and domestic sewage (Carvalho and Santos 2016). After antibiotic effluent is treated by Anoxic/Oxic process in WWTPs, there are still some remaining antibiotics with concentrations of $\mathrm{ng}-\mathrm{mg} \cdot \mathrm{L}^{-1}$ directly discharged into the environment, because conventional WWTPs are not specifically designed to remove these microbial toxicity pollutants (Cui et al. 2020). Li et al. (2018) reported the total antibiotic effluent concentration of $0.49-2.6 \mu \mathrm{g} \cdot \mathrm{L}^{-1}$ after acidification and anaerobic treatments in a typical pharmaceutical plant. Wang et al. (2016) detected $11 \mathrm{ng} \cdot \mathrm{L}^{-1}$ of florfenicol and $7.6 \mathrm{ng} \cdot \mathrm{L}^{-1}$ of thiamphenicol in tap water in Shanghai, China. Antibiotics are refractory to be biodegraded, meanwhile, the chronic toxicity of antibiotics can inhibit microbial activity, and cause the death of effective microorganisms in sewage treatment facilities, and further affect the decomposition efficiency of organic matter in wastewater (Tomlinson et al. 2010). In the meantime, the long-term domestication of antibiotics will inevitably induce various antibiotic resistance genes (ARGs) in sludge microorganisms (Zhang et al. 2020). Then, these microbes may be transformed into drug-resistant pathogenic microorganisms, which will enter the water environment, attack advanced organisms, endanger the safety of human body, and cause secondary pollution (Elder et al. 2020). Jutkina et al. (2016) pointed out a very low concentration of tetracycline $\left(10 \mu \mathrm{g} \cdot \mathrm{L}^{-1}\right)$ could promote the horizontal transfer of multiple antibiotic resistance. Therefore, the reduction of antibiotic concentration before entering the biological wastewater treatment process is of great importance.

Currently, sulfonamides (SAs) are some of the most commonly used broad-spectrum antibiotics for various bacterial infectious disease treatment and feed additives (Fei et al. 2016). Carvalho and Santos (2016) found SAs were the most frequently analyzed and detected antibiotics in water. Because of the hydrophilic nature of SAs, traditional WWTPs processes and the state-of-the-art post-treatment technologies, such as sand filtration, coagulation, flocculation, and flotation, are unable to remove SMX thoroughly (Nakada et al. 2007). Therefore, more studies now try to find advanced large capacity adsorbents to remedy ineffective antibiotic treatment in the traditional sewage treatment process. Generally, commercial activated carbon, graphene oxide, carbon nanotubes, and other porous materials are expensive and inefficient for antibiotic adsorption (Ndirangu et al. 2019). Therefore, biochar has gradually come into view because of its low cost and high adsorption ability (Dutta et al. 2019).

Biochar is a material with a large specific surface area, high hydrophobicity, and aromaticity (Jiao et al. 2021). It is a refractory, stable, environmentally friendly carbon-rich product produced in anaerobic or anoxic conditions from agricultural and forestry residues (Emma 2006; Hayes 2006). Many researchers used biochar to remove hydrophobic organic pollutants like SAs (Wu et al. 2020). The properties of biochar containing specific surface area, microporosity, and surface chemistry directly affect the adsorption efficiency of antibiotics (Yang et al. 2020). The unmodified biochar usually shows low adsorption quantity and weak anti-interference ability for its insufficient properties, and often fails to meet the requirements of antibiotic treatment in wastewater (Han et al. 2013). Usually, there are two main purposes of biochar modification for antibiotic removal: (1) to increase the surface area of biochar; (2) to increase the surface functional groups of biochar. The enhanced porosity and richer functional groups fatefully endow adsorbent with stronger adsorption ability (Tang et al. 2018). Generally, the introduction of micropores onto biochar can be achieved by physical or chemical activation (Li et al. 2020). But the high silica content in agricultural residues remains a barrier towards synthesizing biochar with large surface area. 
Previous studies have reported $\mathrm{NaOH}$ or $\mathrm{KOH}$ solution at a high temperature are effective in removing silica from biomass (Muniandy et al. 2014). Furthermore, the $\mathrm{KOH}$ activation is a compelling method for creating highly microporous structure and functional groups on the surface of the carbon (Fu et al. 2018). For instance, Ling et al. (2016) mixed shrimp shell biochar with $\mathrm{KOH}$ at different mass ratios and further carbonized it at $700-850^{\circ} \mathrm{C}$. The activated biochar presented a hierarchical porous structure with the maximum specific surface area of $3171 \mathrm{~m}^{2} \cdot \mathrm{g}^{-1}$, and the maximum sulfamethazine adsorption quantity of $699.3 \mathrm{mg} \cdot \mathrm{g}^{-1}$, which was far greater than that nonactivation.

Therefore, this study aimed to prepare alkali active porous biochar adsorbent to remove SAs SMX from waste water. The specific objective was to prepare biochar materials with large specific surface area, with the physical, chemical and structural information characterized in detail. The batch method was explored to evaluate the adsorption properties of biochar on SMX by adsorption kinetic model and, isothermal adsorption model. The adsorption mechanism was also inferred.

\section{Materials and methods}

\subsection{Materials}

SMX (98.0\%) was purchased from Aladdin Industrial Co., China. All other chemicals used in this paper were of analytical grade. The corn cob xylose residue (CCR) was obtained from Shandong Longlive Bio-Technology Co., Ltd., China.

\subsection{Preparation of biochar}

After removing impurities, CCR was crushed with pulverizer, sifted through 40 meshes sieve, and dried overnight at $105^{\circ} \mathrm{C}$. Then, $\mathrm{CCR}$ was impregnated in $1 \mathrm{~mol} \cdot \mathrm{L}^{-1} \mathrm{NaOH}$ solution at a ratio of 1:20 $(\mathrm{m}: \mathrm{V})$ at room temperature for $24 \mathrm{~h}$, and the mixture was elutriated with deionized water until the washing liquid was close to neutral. The sample was pyrolyzed at $400^{\circ} \mathrm{C}$ under nitrogen protection for $1 \mathrm{~h}$ in a tube furnace. The obtained precursor biochar was named as AM400.

After the demineralization treatment, AM400 was evenly mixed with $\mathrm{KOH}$ particles at a mass ratio of $1: 5$ with a tiny bit of water and dried at $105{ }^{\circ} \mathrm{C}$ for $12 \mathrm{~h}$ in a vacuum oven. Then the sample was moved into the tube furnace and calcined by stages under the protection of nitrogen gas. After rising to $600{ }^{\circ} \mathrm{C}$ at the heating rate of $5{ }^{\circ} \mathrm{C} \cdot \mathrm{min}^{-1}$, the pyrolysis temperature rose to $850{ }^{\circ} \mathrm{C}$ at the rate of $3{ }^{\circ} \mathrm{C} \cdot \mathrm{min}^{-1}$ and maintained for $1 \mathrm{~h}$. Next, the biochar was soaked in $1 \mathrm{~mol} \cdot \mathrm{L}^{-1} \mathrm{HCl}$ solution, oscillated for $4 \mathrm{~h}$ to eliminate inorganic components after cooling to room temperature, and washed with hot deionized water until the washing fluid became neutral. Finally, the biochar was oven-dried and named as $850 \mathrm{BC}$.

\subsection{Characterizations of the biochar}

Biochar was characterized for specific surface area, total pore volume and average pore width by BET test (Brunauer-Emmett-Teller, Quantachrome Corp., Micromeritics Nove 2000e apparatus, USA), surface morphology by scanning electron microscopy (SEM, Zeiss, Supra55 Sapphire, Japan), elements content with SEM-EDS (Energy Dispersive X-ray spectrometer), and the change of surface groups by Fourier transform infrared spectroscopy (FTIR, PerkinElmer Inc., Spectrum One, USA). The groups on biochar surface were quantified by acid-base titration intermittent balance method. $50.00 \mathrm{mg}$ biochar was accurately weighed in $250 \mathrm{~mL}$ of PTFE beaker with $50 \mathrm{~mL}$ ultrapure water. The biochar was titrated by a self-titrator at a fixed rate with $0.01 \mathrm{~mol} \cdot \mathrm{L}^{-1} \mathrm{NaOH}$ and $\mathrm{HCl}$ volumetric solution. The titration was protected in $\mathrm{N}_{2}$ atmosphere to avoid the effect of $\mathrm{CO}_{2}$ in air on $\mathrm{pH}$. The $\mathrm{pH}$ meter was used to measure the change of $\mathrm{pH}$ while each acid/base drop was added.

\subsection{Batch adsorption experiments}

The adsorption kinetics was investigated with $5 \mathrm{mg} 850 \mathrm{BC}$ and $50 \mathrm{~mL}$ SMX solution. Bottles were set in a shaker at the rate of $180 \mathrm{rpm}$ at $30^{\circ} \mathrm{C}$ for $24 \mathrm{~h}$ in the dark. At each sampling time 1-3 mL solution was separated and filtrated through $0.22 \mu \mathrm{m}$ filter membrane. For adsorption isotherms, different dosages of $850 \mathrm{BC}$ were added in $50 \mathrm{~mL}$ of $300 \mathrm{mg} \cdot \mathrm{L}^{-1} \mathrm{SMX}$ solutions. The mixtures were shaken at $10-30^{\circ} \mathrm{C}$. The control experiment was conducted in SMX solution without biochar. All adsorption data were run in triplicate and the average values were reported.

The concentrations of SMX in the sample were analyzed by high performance liquid chromatography (UPLC, Agilent Technologies 1290 Infinity II, USA) and ZORBAX RRHD Eclipse Plus C18 column $(2.1 \times 50 \mathrm{~mm}, 1.8 \mu \mathrm{m}$, Agilent $)$ with a UV detector at $263 \mathrm{~nm}$. The mobile phase conditions were acetonitrile: $0.1 \%(w t)$ formic acid $(50: 50, V: V)$ at a flow rate of $0.05 \mathrm{~mL} \cdot \mathrm{min}^{-1}$ by $10 \mu \mathrm{L}$ injection.

\subsection{Analytical models and data analysis}

The adsorption quantity of biochar for SMX was calculated as follows:

$q_{e}=\left(c_{0}-c_{e}\right) V / m$

$R=c_{e} / c_{0}$ 
where $q_{e}$ is the adsorption quantity of SMX on biochar at equilibrium, $\mathrm{mg} \cdot \mathrm{g}^{-1}$; $\mathrm{R}$ is the removal rate of SMX on biochar, $\% ; c_{0}$ is the initial concentration of SMX, $\mathrm{mg} \cdot \mathrm{L}^{-1} ; c_{e}$ is the remaining concentration of SMX at equilibrium, $\mathrm{mg} \cdot \mathrm{L}^{-1}$; $V$ is the volume of system, $\mathrm{mL} ; m$ is the mass of adsorbent, g.

In order to investigate the main impetus of adsorption process of SMX onto 850BC, the adsorption kinetic data were fitted to the Pseudo-first order kinetic model, Pseudo-second order kinetic model, and Intraparticle diffusion model. These kinetic models can be represented as follows:

Pseudo-first order kinetic model:

$q_{t}=q_{e}\left[1-\exp \left(k_{1} t\right)\right]$

Pseudo-second order kinetic model:

$t / q_{t}=t /\left(k_{2} q_{e}^{2}\right)+t / q_{e}$

Intraparticle diffusion model:

$q_{t}=k_{i} t^{1 / 2}+C$

where $q_{t}$ is the SMX adsorption quantity, $\mathrm{mg} \cdot \mathrm{g}^{-1} ; k_{1}$ is the pseudo-first rate constant, $\min ^{-1} ; k_{2}$ is the pseudo-second rate constant, $\mathrm{g} \cdot \mathrm{mg}^{-1} \cdot \mathrm{min}^{-1} ; k_{i}$ is the intraparticle diffusion model rate constant, $\mathrm{g} \cdot \mathrm{mg}^{-1} \cdot \mathrm{min}^{-1 / 2} ; C$ is the intercept, $\mathrm{mg} \cdot \mathrm{g}^{-1}$. The pseudo-first-order and pseudo-secondorder kinetic models describe the monolayer and multilayer adsorption, respectively, intraparticle diffusion model is used to determine the rate-limiting step of the adsorption process.

The isothermal adsorption data were fitted to the Langmuir and Freundlich isothermal adsorption models. These isotherm models can be represented as follows:

Langmuir model:

$c_{e} / q_{e}=1 /\left(q_{\max } K_{L}\right)+c_{e} / q_{\max }$

Freundlich model:

$\ln q_{e}=\ln K_{F}+\ln c_{e} / n$

where $q_{\max }$ is the maximum adsorption quantity, $\mathrm{mg} \cdot \mathrm{g}^{-1} ; K_{L}$ is Langmuir model adsorption capacity constant, $\mathrm{L} \cdot \mathrm{mg}^{-1} ; K_{F}$ is Freundlich adsorption capacity constant, $\mathrm{mg}^{1-\mathrm{n}} \cdot \mathrm{g}^{-1} \cdot \mathrm{L}^{\mathrm{n}}$; $1 / n$ is Freundlich adsorption intensity constant. The Langmuir model describes monolayer sorption on a homogenous surface and the Freundlich model explains a multi-layer adsorption process.

To determine the conformity degree of the Langmuir isothermal model to adsorption process, the isotherm was classified by the separation factor $\mathrm{R}_{\mathrm{L}}$, which was defined in Eq. (8):

$R_{L}=1 /\left(1+K_{L} c_{0}\right)$
Table 1 Component content of corn cob residue

\begin{tabular}{lcccc}
\hline Material & Cellulose & Hemicellulose & Lignin & \multicolumn{1}{c}{ Ash } \\
\hline Corn cob & $34.93 \%$ & $30.90 \%$ & $20.07 \%$ & $2.32 \%$ \\
Corn cob residue & $57.43 \%$ & $3.47 \%$ & $28.08 \%$ & $10.75 \%$ \\
\hline
\end{tabular}

Table 2 Si content of samples (SEM-EDS)

\begin{tabular}{llll}
\hline CCR & Ash & AM400 without Si removal & AM400 \\
\hline $18.99 \%$ & $31.10 \%$ & $0.37 \%$ & $<0.01 \%$ \\
\hline
\end{tabular}

where $R_{L}$ is the parameter to measure the difficult degree of adsorption process, dimensionless parameter; $c_{0}$ is the initial concentration of SMX solution, $\mathrm{mg} \cdot \mathrm{L}^{-1} ; K_{L}$ is the Langmuir model adsorption capacity constant, $\mathrm{L} \cdot \mathrm{mg}^{-1}$.

\section{Results and discussion}

\subsection{Preparation and characterization of $\mathbf{8 5 0}$}

\subsubsection{Silicon removal of corncob waste residue}

To increase the solidity of the waste residue, sand was added into corncob residue after xylose production. Thus, CCR contained $10.75 \%$ ash (Table 1), which was approximately 5 times that of raw corncob, and one third of the ash content was $\mathrm{SiO}_{2}$ (Table 2). It was believed that inorganic components could block pore entrance and inhibit pore evolution in the process of carbonization and activation (Chang et al. 2003). Therefore, removing minerals from precursor materials to minimize inorganic components was the prerequisite for producing porous biochar with high surface area. The pretreatment method of $\mathrm{NaOH}$ solution dipping and washing was employed to remove the mixed silicon impurities in the CCR to obtain porous biochar.

$\mathrm{SiO}_{2}$, which existed in internal structure of biomass, could be removed by $\mathrm{NaOH}$ solution dipping and repeatedly water cleaning after carbonization. Thus, as shown in Fig. 1, the presence of $\mathrm{Si}-\mathrm{O}-\mathrm{Si}$ in $\mathrm{CCR}$ could be identified by the appearance of peak at $1070 \mathrm{~cm}^{-1}$ (Tang et al. 2018; Yan et al. 2017), and the peak no longer appeared after pyrolysis at $400^{\circ} \mathrm{C}$. Therefore, it justified the successful completion of the procedure of pre-carbonization for silicon removal. The presence of Si element was not detected in AM400 by SEM-EDS measurement, which also proved the success of pre-carbonization process for silicon removal (Table 2). 


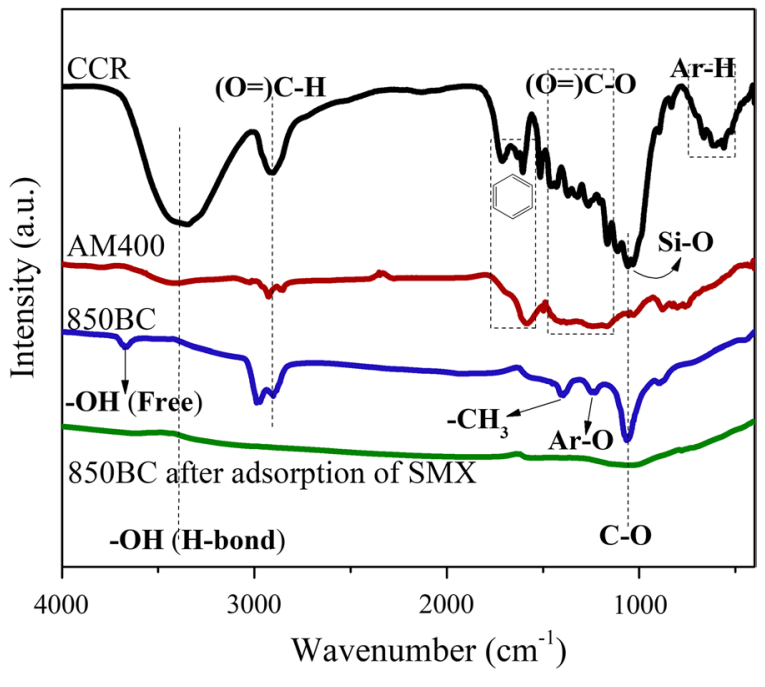

Fig. 1 FTIR spectra of raw material CCR and biochars

\subsubsection{Characterization of biochars}

The typical SEM micrographs of raw material CCR, pre-carbonation material AM400 and activated biochar $850 \mathrm{BC}$ were illustrated in Fig. 2. The CCR presented a flat and smooth surface with no clear porous structure (Fig. 2a). Then a small amount of pore began to present on the surface of AM400 after pre-carbonation at $400{ }^{\circ} \mathrm{C}$ (Fig. 2b). In contrast to CCR, the roughness degree of surface of $850 \mathrm{BC}$ increased, and the apparent porous structure could be observed after $\mathrm{KOH}$ activation and carbonization at $850{ }^{\circ} \mathrm{C}$ (Fig. 2c). It demonstrated that $\mathrm{KOH}$ activation under high temperature could improve porosity and porous structure of biochar. This phenomenon was due to the reaction:

$2 \mathrm{KOH}+2 \mathrm{C} 2 \mathrm{~K}+2 \mathrm{CO}+\mathrm{H}_{2}$

$\mathrm{KOH}$ produced flowing metals $\mathrm{K}$ and $\mathrm{CO}$ during activation at high temperature. Diffusion of $\mathrm{K}$ and $\mathrm{CO}$ into carbon interior contributed to well-developed micropores and macropores (Cheng et al. 2017; Shi et al. 2017). KOH had stronger activation and intercalation ability than $\mathrm{NaOH}$ and smaller $\Delta \mathrm{G}$ when reacting with $\mathrm{C}$ at high temperature (LilloRódenas et al. 2003), it's the reason for choosing $\mathrm{KOH}$ for pore formation.

The influence of $\mathrm{KOH}$ activation on the specific surface area $\left(S_{B E T}\right)$, pore volume $\left(V_{t}\right)$ and pore diameter $\left(D_{a p}\right)$ of biochar was compared as showin in Table 5. The $S_{B E T}$ of $850 \mathrm{BC}$ increased significantly from $14.8 \mathrm{~m}^{2} \cdot \mathrm{g}^{-1}$ for AM400 to 3043 $\mathrm{m}^{2} \cdot \mathrm{g}^{-1}$, which was approximately 200 -fold and the $V_{t}$ was approximately eightfold. The pore diameter distribution curves (Fig. 3a) showed the shift of mesopore to micropore after modification. The pore diameter of $850 \mathrm{BC}$ was mainly distributed in $1-4 \mathrm{~nm}$. It proved that $\mathrm{KOH}$ treatment was especially suitable for development of micropore and obtainment of extremely high surface area.

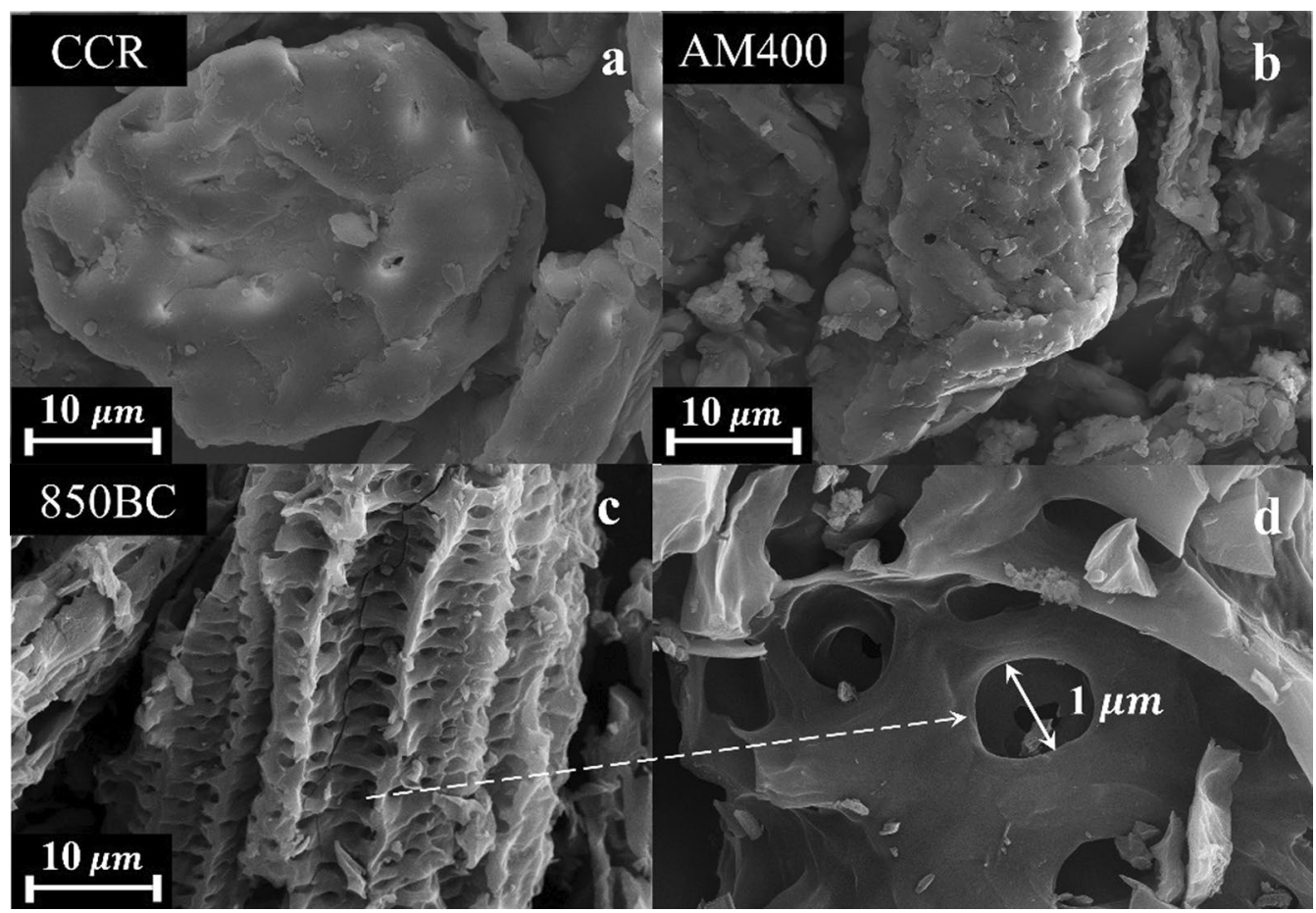

Fig. 2 SEM images of raw material and biochars a) CCR, b) AM400, c) and d) 850BC 

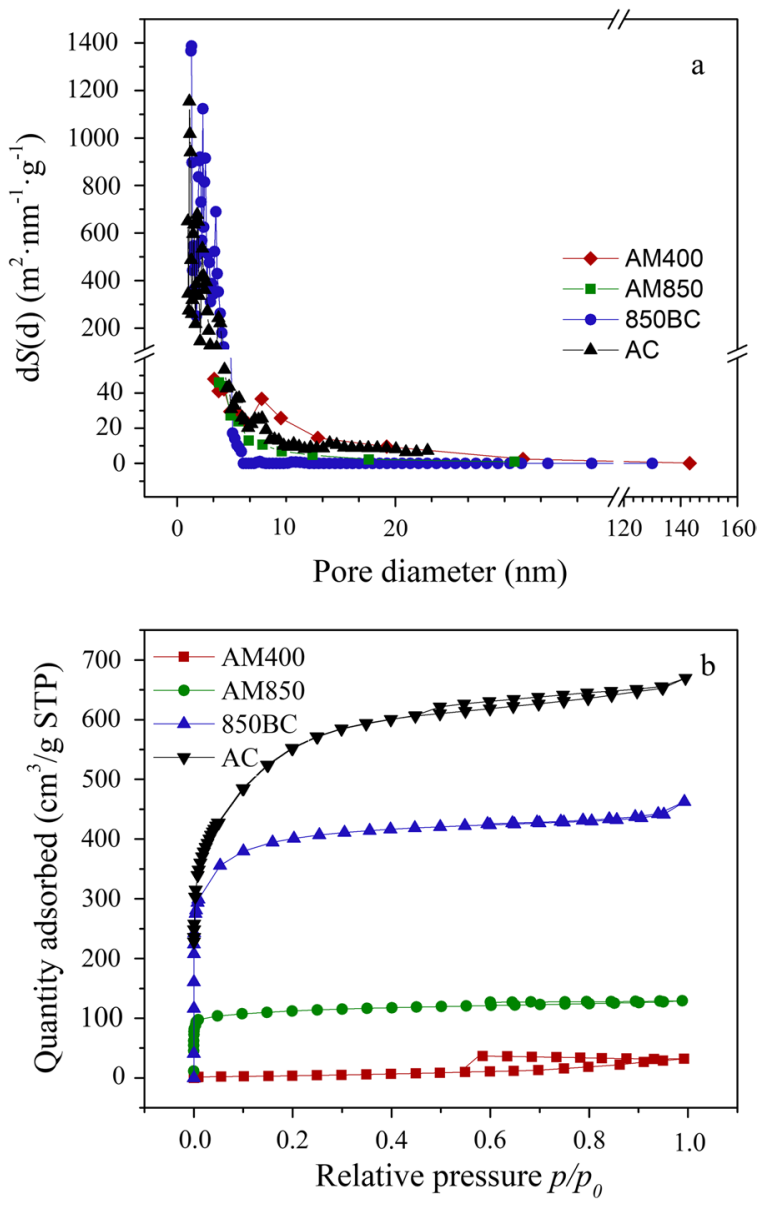

Fig. 3 a Pore size distribution curves of biochars; $\mathbf{b} \mathrm{N}_{2}$ adsorptiondesorption curves of biochars

The $\mathrm{N}_{2}$ adsorption-desorption isotherms also supported the conclusions above. As shown in Fig. 3b, the adsorption-desorption isotherm of AM400 belonged to the Type IV according to adsorption theory, AM400 contained few pores and even less micropore (Huang et al. 2020). Meanwhile, AM400 exhibited an apparent $\mathrm{H} 2$ hysteresis loop at $p / p_{0}>0.5$, which was associated with capillary condensation in mesopores. The type $\mathrm{H} 2$ hysteresis loop reflected the complex pore structure of AM400, which might include typical "ink bottle" pores, tube-shaped pores with uneven pore size distribution, and interstitial pores of close-packed spherical particles (Wang et al. 2017a, b). As to 850BC, a typical micropore material, it was confirmed by type II isotherms and an obvious type $\mathrm{H} 4$ hysteresis loop with the character of almost horizontal parallel adsorption-desorption isotherm. The type $\mathrm{H} 4$ loop was associated with narrow slit-like micropores and micropores embedded in the macropores, while the type $\mathrm{H} 2$ loop often occurred in pores with narrow necks and wide bodies. It indicated that the $\mathrm{KOH}$ activation at $850{ }^{\circ} \mathrm{C}$ changed the pore shape, caused the larger pores to collapse and developed smaller micropores of AM400
(Zhu et al. 2018). Compared with the detection of the concentrated micropore with BET, SEM graphs exhibited many macropores about $1 \mu \mathrm{m}$ in diameter on $850 \mathrm{BC}$ surface (Fig. 2d). Accordingly, the internal micropores of 850BC were connected to the inner wall of the surface micropores so that the multi-level pore structure of $850 \mathrm{BC}$ was formed. Certainly, the increased SSA and pore volume could provide more favorable adsorption sites for antibiotics. According to the adsorption theory, the pore size of adsorbent should match the geometric size of adsorbate molecules or ions for effective utilization. When the pore size of adsorbent is 1.7-3 times larger than the adsorbate molecule, the adsorbent will show the best adsorption performance (Tang et al. 2018). The molecule dimension of SMX was approximately $1.49 \times 0.64 \times 0.56 \mathrm{~nm}$, and the pore diameter of $850 \mathrm{BC}$ was concentrated in 2-4 nm (Fig. 3a), which was 1.3-3 times molecular volume of SMX. It was reasonable to expect that the $850 \mathrm{BC}$ was suitable for effective and fast adsorption of SMX with sufficient pore size.

The FT-IR spectra in Fig. 1 indicated that biochar consisted of several functional groups, which could be mutually confirmed with results of acid-base titration in Table 5. The broad peaks appearing at approximately $3440 \mathrm{~cm}^{-1}$ were attributed to the presence of associative hydrogen bond of O-H. As can be seen, CCR exhibited the highest peak intensity of $\mathrm{O}-\mathrm{H}$, then $\mathrm{O}-\mathrm{H}$ peaks were gradually weakened after pyrolysis because of the decomposition of cellulose and lignin (Yang et al. 2007). A series of peaks in the region of $1500-1700 \mathrm{~cm}^{-1}, 1100-1460 \mathrm{~cm}^{-1}$ and $600-710 \mathrm{~cm}^{-1}$ of CCR could be associated to the frame vibration of aromatic $\mathrm{C}=\mathrm{C}$, the stretching vibration of carboxyl and anhydride, and the out-of-plane vibration of $\mathrm{C}-\mathrm{H}$, respectively (Tang et al. 2018). The above peaks also weakened or even faded away after carbonization for the same reason with hydroxyl, only skeleton vibration peaks of aromatic $\mathrm{C}=\mathrm{C}$ and stretching vibration peaks of $\mathrm{C}-\mathrm{O}$ remained in $\mathrm{AM} 400$ and $850 \mathrm{BC}$.

\subsection{Adsorption capacity of SMX on 850BC}

\subsubsection{Adsorption kinetics}

The adsorption of SMX onto 850BC at different times was listed in Fig. 4. The adsorption of SMX showed two phases: (i) The adsorption quantity increased rapidly in the initial stage during the first $30 \mathrm{~min}$. Because in the initial stage, there were a large number of exposed active sites on $850 \mathrm{BC}$ surface, SMX molecules rapidly diffused to $850 \mathrm{BC}$ surface for surface adsorption. (ii) The adsorption quantity slowly increased after 30 min until reaching the adsorption equilibrium, because the adsorption of SMX from the surface to the internal pore was hindered by intermolecular collision and the inter-channel extrusion, and the active sites were gradually occupied. As a result, the maximum 

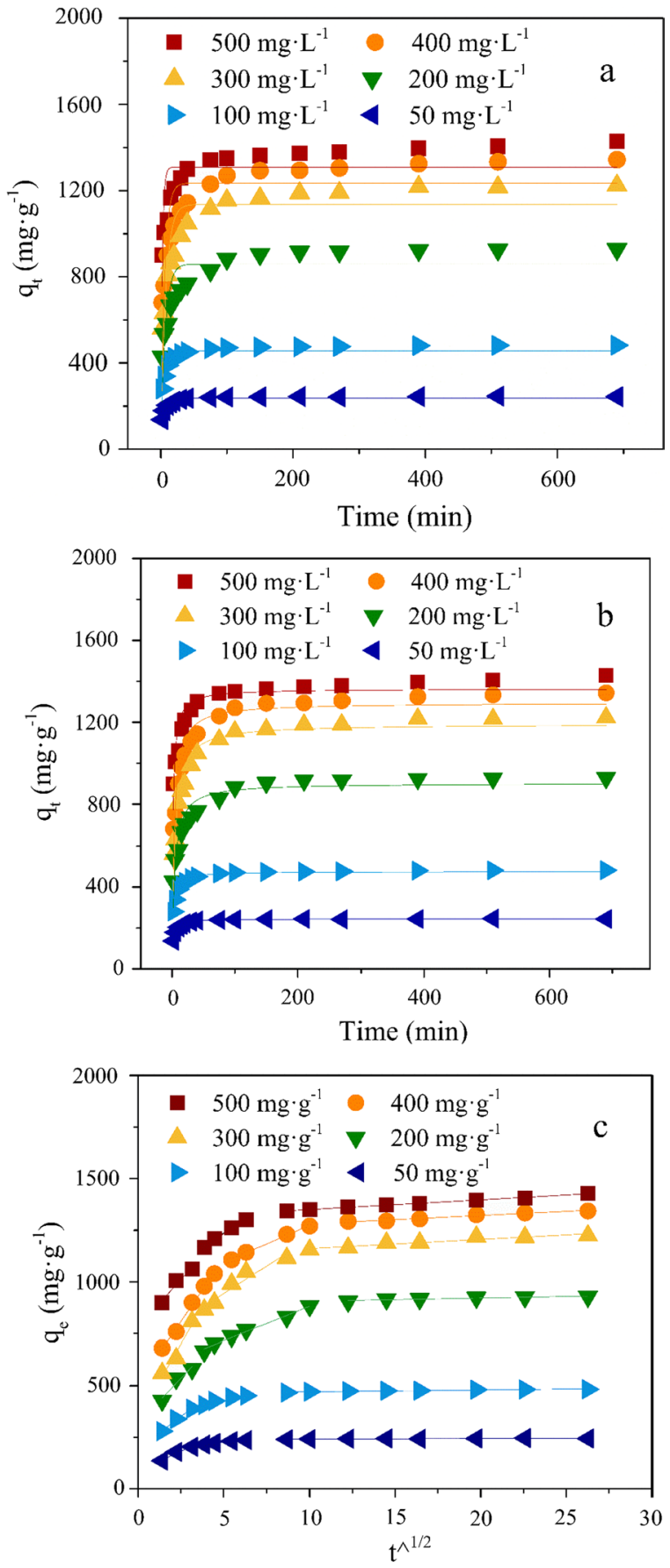

Fig. 4 Adsorption kinetics model fitting curves of SMX on 850BC with different concentrations of SMX. a pseudo-first order kinetic model; b pseudo-second order kinetic model; $\mathbf{c}$ intraparticle diffusion model

adsorption quantity was $1429 \mathrm{mg} \cdot \mathrm{g}^{-1}$, and the maximum removal rate was up to $98.52 \%$. This phenomenon became more pronounced with the increase of initial SMX concentration, with a growth of the adsorption quantity and the time required for adsorption to reach equilibrium.
The plots of the different kinetics models for SMX adsorption onto 850BC were described in Fig. 4. The calculated values of $q_{\mathrm{e}}$ and correlation coefficient $\left(R^{2}\right)$ were listed in SI, Table S2. It could be observed that the pseudosecond-order (PSO) kinetics model, which showed the highest $R^{2}$ and $q_{\mathrm{e}}$, provided a better fit for adsorption process and a good agreement with the experimental data. The PSO model assumed the adsorption of adsorbate on adsorbent was chemisorption, and that the rate-limiting step might be a chemical reaction or a chemisorption process via sharing or exchanging electrons between biochar and SMX molecules, since the aromatic skeleton structure in the molecular structure of SMX (SI, Fig. S1) is easily combined in the form of $\pi-\pi$ conjugate with the aromatic structure and the surface oxygen-containing functional groups of biochar.

Figure $4 \mathrm{c}$ illustrated the intraparticle diffusion model. The intraparticle diffusion model was employed to analyze the adsorption kinetics further, and the calculated values were listed in SI, Table S3. As seen in Fig. 4c, none of the linear intercepts was positive, indicating that both surface sorption and intraparticle diffusion contributed to SMX sorption process onto $850 \mathrm{BC}$. In the initial phase, SMX rapidly diffused through solution to the bare exterior surface sorption sites on $850 \mathrm{BC}$ as a boundary layer diffusion step. The initial concentration provided the driving force to overcome mass transfer resistance between solid and liquid phases. The adsorption rate was much higher than the desorption rate at that moment. The $\mathrm{C}$-value helped determine the boundary thickness: the larger the $\mathrm{C}$ value, the greater the boundary layer diffusion effect (Wu 2007). The C-value increased with the initial SMX concentration, indicating an enhanced diffusion effect in the boundary layer. The secondary stage was the intraparticle diffusion across macropores on the surface of $850 \mathrm{BC}$ and with the gradual sorption, the adsorption rate gradually slowed down because of the hindrance of intermolecular collision and inter-porous-channel extrusion, and the active sites on biochar were occupied increasingly. In the third stage, SMX molecules moved through narrow pore channels to the micro-mesoporous of interior $850 \mathrm{BC}$, the intraparticle diffusion rate was obviously lower than the former stage of surface diffusion. Finally, the adsorption rate was equivalent to the desorption rate, the surface adsorption tended to be balanced.

\subsubsection{Adsorption isotherms}

The isothermal model fitting curves for SMX adsorption onto 850BC were presented in Fig. 5. The calculated data were listed in Table 3. Although both isothermal models described the experimental data well, the Langmuir model obviously fitted the isotherms better at low temperature. It illustrated the monolayer adsorption of SMX on 850BC tended to be dominant at low temperature and gradually 

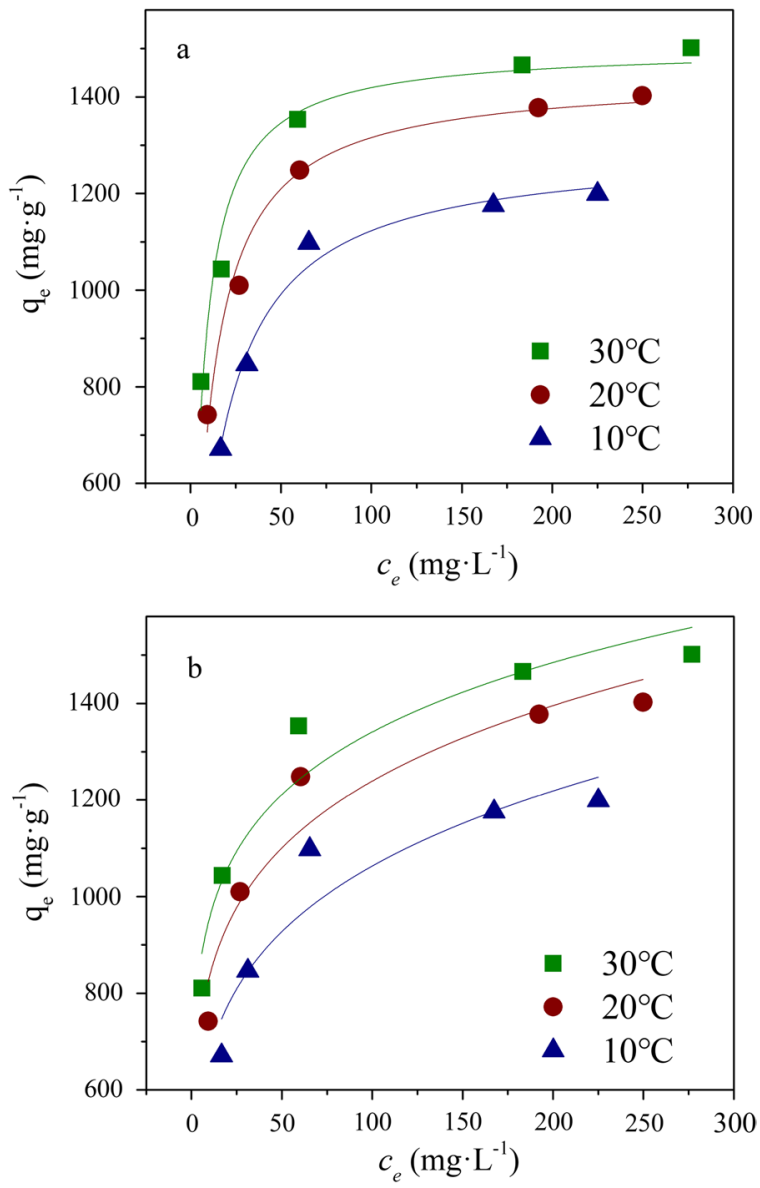

Fig. 5 Adsorption isothermal model fitting curves of SMX on 850BC under different temperatures. a Langmuir isothermal model; b Freundlich isothermal model shifted to multilayer adsorption at room temperature. The value of $1 / \mathrm{n}$ between $0-0.5$ indicated the adsorption was a preferential process in the Freundlich isotherm. The values of $R_{L}$ were listed in Table 3 . When $R_{L}>1$, the adsorption process was difficult to carry out, and the adsorption effect was poor; when $R_{L}=0$, the adsorption process was irreversible; when $0<R_{L} \leq 1$, the adsorption process was favorable (Zhu et al. 2014). In this work, the $R_{L}$ values were found within the range of $0.01-0.05$ for SMX adsorption onto $850 \mathrm{BC}$, which suggested that the adsorption process was favorable and easily accessible.

The maximum adsorption capacities of $850 \mathrm{BC}$ in this study by comparison with other previously reported biochar for the antibiotic adsorption were listed in Table 4, and the SMX adsorption quantity onto $850 \mathrm{BC}$ was much higher than other records. Such contrast also exhibited that $850 \mathrm{BC}$ might be an effective adsorbent for SMX removal from polluted water.

\subsection{Adsorption mechanisms of SMX on 850BC}

The adsorptive and structural performance comparisons of raw material CCR, precursor AM400, biochar product $850 \mathrm{BC}$ and industrial activated carbon $\mathrm{AC}$ were listed in Table 5. The adsorption capacity of $850 \mathrm{BC}$ was much higher than unactivated biochar AM850 at the same pyrolysis temperature. Micropores dominated the pore size distribution of AM850 and the shape of adsorption-desorption curve was also the same as $850 \mathrm{BC}$ (Fig. 3). It showed that both biochars presented similar hole shapes at the same carbonization temperature, while the $850 \mathrm{BC}$ contained 7 times of
Table 3 Adsorption kinetics model fitting data of SMX on $850 \mathrm{BC}$
Table 4 Adsorption isotherms model fitting data of SMX on $850 \mathrm{BC}$

\begin{tabular}{lclcccr}
\hline$c_{S M X}\left(\mathrm{mg} \cdot \mathrm{L}^{-1}\right)$ & 50 & 100 & 200 & 300 & 400 & 500 \\
\hline $\mathrm{q}_{\mathrm{e} \text { exp }}\left(\mathrm{mg} \cdot \mathrm{g}^{-1}\right)$ & 244.05 & 482.13 & 928.17 & 1223.64 & 1343.59 & 1429.09 \\
Pseudo-first-order kinetic model & & & & & \\
$\mathrm{q}_{\mathrm{e}}\left(\mathrm{mg} \cdot \mathrm{g}^{-1}\right)$ & 235.82 & 457.17 & 858.91 & 1135.77 & 1234.70 & 1308.58 \\
$k_{l}\left(\mathrm{~min}^{-1}\right)$ & 0.3331 & 0.3402 & 0.1478 & 0.1356 & 0.1778 & 0.4309 \\
$\mathrm{R}^{2}$ & 0.8206 & 0.7128 & 0.6443 & 0.7075 & 0.6191 & 0.4902 \\
Pseudo-second-order kinetic model & & & & & \\
$\mathrm{q}_{\mathrm{e}}\left(\mathrm{mg} \cdot \mathrm{g}^{-1}\right)$ & 244.62 & 475.3494 & 902.5613 & 1190.609 & 1294.736 & 1363.052 \\
$k_{2}\left(\mathrm{~g} \cdot \mathrm{mg}^{-1} \cdot \mathrm{min}^{-1}\right)$ & 0.00234 & 0.00119 & 0.00028 & 0.00020 & 0.00023 & 0.00048 \\
$\mathrm{R}^{2}$ & 0.9914 & 0.9597 & 0.8898 & 0.9152 & 0.8860 & 0.8499 \\
\hline
\end{tabular}

\begin{tabular}{lllllllll}
\hline $\begin{array}{l}\mathrm{T} \\
\left({ }^{\circ} \mathrm{C}\right)\end{array}$ & Langmuir & & & & & Freundlich \\
\cline { 2 - 3 } & $\begin{array}{l}\mathrm{q}_{\max } \\
\left(\mathrm{mg} \cdot \mathrm{g}^{-1}\right)\end{array}$ & $\begin{array}{l}K_{L} \\
\left(\mathrm{~L} \cdot \mathrm{mg}^{-1}\right)\end{array}$ & $\mathrm{R}^{2}$ & $R_{L}$ & & $\begin{array}{l}K_{F} \\
\left(\mathrm{mg}^{1-\mathrm{n}} \mathrm{L}^{\mathrm{n}} \mathrm{g}^{-1}\right)\end{array}$ & $1 / \mathrm{n}$ & $\mathrm{R}^{2}$ \\
\hline 10 & 1294.77 & 0.0654 & 0.9803 & 0.0485 & 428.77 & 0.197 & 0.8586 \\
20 & 1442.54 & 0.1038 & 0.9820 & 0.0311 & 562.87 & 0.172 & 0.9060 \\
30 & 1501.20 & 0.1732 & 0.9592 & 0.0189 & 681.31 & 0.147 & 0.9218 \\
\hline
\end{tabular}


Table 5 Performance comparison of biochars

\begin{tabular}{lccccc}
\hline Biochar & CCR & AM400 & AM850 & $850 \mathrm{BC}$ & AC \\
\hline $\begin{array}{l}\text { Adsorption quantity } \\
\left(\mathrm{mg}^{-1}\right)\end{array}$ & 15.29 & 18.35 & 256.94 & 1429.09 & 134.01 \\
$\begin{array}{l}\text { Pore structure } \\
\mathrm{S}_{\mathrm{BET}} \\
\left(\mathrm{m}^{2} \cdot \mathrm{g}^{-1}\right)\end{array}$ & 5.50 & 14.75 & 431.74 & 3043 & 2025 \\
$V_{t}$ & 0.01 & 0.05 & 0.20 & 1.67 & 2.04 \\
$\left(\mathrm{~cm}^{3} \cdot \mathrm{g}^{-1}\right)$ & & & & & \\
$\begin{array}{l}\text { Dap } \\
(\mathrm{nm})\end{array}$ & 7.77 & 13.34 & 1.91 & 2.23 & 1.03 \\
$\begin{array}{l}\text { Surface functional } \\
\text { groups (mmol.g }\end{array}$ & & & & & \\
Carboxyl & & & & & \\
Lactone base & - & 41.05 & 38.98 & 11.34 & 6.02 \\
Phenolic hydroxyl & - & 0.07 & 0.35 & 0.18 & - \\
\hline
\end{tabular}

the surface area and 8 times of the pore volume of AM850 as adsorptive sites for SMX, causing a massive difference in adsorption capacity. Through simple linear fitting (SI Fig. S2), it could be confirmed that the adsorption quantity of biochar derived from corncob residue was positively associated with surface area.

Simultaneously, compared with representative commercial microporous carbon-active carbon (AC), 850BC presented 1.5 times the specific surface area and 10 times the adsorption quantity (Table 5), and AM850 presented a fifth of the specific surface area and twice the adsorption quantity. It proved that the surface functional groups also participated in the adsorption process. In FTIR spectrogram Fig. 1, the $\mathrm{O}-\mathrm{H}$ peaks at $3440 \mathrm{~cm}^{-1}$ disappeared after adsorption, proving hydroxyl on the $850 \mathrm{BC}$ surface participated in the sorption process. Similarly, the stretching vibration peak of aldehyde group C-H at $2900 \mathrm{~cm}^{-1}$ (Jia et al. 2013) vanished after sorption, which also demonstrated that aldehyde group was involved in the SMX adsorption. The peak of $1060 \mathrm{~cm}^{-1}$ in the spectra was due to the disappearance of the stretching vibration of $\mathrm{C}-\mathrm{O}$ (Wang et al. 2017a, b) after sorption. Although the number of acidic carboxy groups on the 850BC surface was greatly reduced compared to AM850, the phenolic hydroxyl was significantly increased due to the action of alkali. Likewise, Ling (Ling et al. 2016) prepared $\mathrm{KOH}$ activated shrimp shell biochar with the surface area of 3171 $\mathrm{m}^{2} \cdot \mathrm{g}^{-1}$ and a similar pore structure with $850 \mathrm{BC}$, but the SMX adsorption quantity of $699.3 \mathrm{mg} \cdot \mathrm{g}^{-1}$ was much smaller than that of 850BC. Due to a higher polarity index $(\mathrm{O}+\mathrm{N}) / \mathrm{C}$ (SI. Table S4), 850BC possesses more functional groups. No matter $-\mathrm{COOH}$ on $\mathrm{AM} 850$ or $-\mathrm{OH}$ on $850 \mathrm{BC}$, the $\pi-\pi$ interaction and $\mathrm{H}$-bond interaction dominated SMX to form chemical bond with multitudinous surface functional groups on biochar that participated in the adsorption process.
Consequently, the overall substantial adsorption property of $850 \mathrm{BC}$ could be attributed to multiple adsorption mechanisms, including the pore filling and $\pi-\pi$ interaction. The pore filling effect matched SMX molecules with the appropriate pore structure, and the significantly enhanced porosity of 850BC could provide more adsorption sites for adsorption. Meanwhile, the $\pi-\pi$ interaction and $\mathrm{H}-$ bond interaction bonded SMX and surface oxygen groups on biochar enhancing specific adsorption.

\section{Conclusions}

Biochar $850 \mathrm{BC}$ was successfully prepared by $\mathrm{KOH}$ activation derived from corncob xylose residue and applied for adsorption of SMX. 850BC presented an extremely high specific surface area of $3043 \mathrm{~m}^{2} \cdot \mathrm{g}^{-1}$, a total pore volume of $1.67 \mathrm{~cm}^{3} \cdot \mathrm{g}^{-1}$, and an average pore diameter of $2.23 \mathrm{~nm}$. The pseudo-second-order kinetic and Langmuir models best fitted the kinetic and isotherm data representing SMX adsorption on 850BC. The maximum adsorption of SMX on $850 \mathrm{BC}$ was $1429 \mathrm{mg} \cdot \mathrm{g}^{-1}$, which was prominently effective, and the removal rate of SMX was up to $98.52 \%$. The excellent adsorption performance of $850 \mathrm{BC}$ was attributed to the developed pore structure and abundant surface oxygencontaining functional groups, while pore filling, $\pi-\pi$ interaction and some other chemisorption dominated the adsorbing mechanism. Thus, we developed an effective and economical way to prepare biochar adsorbent with huge surface area, developed pore structure and abundant surface functional groups. A feasible and superior adsorbent can be applied not only for antibiotic removal but also the potential removal of various water pollutants.

Supplementary Information The online version contains supplementary material available at https://doi.org/10.1007/s42773-021-00128-9.

Acknowledgements This work was supported by the National Key Research and Development Program of China [2017YFA0207201], the National Natural Science Foundation of China (Grant No. 2197020577), School of Chemistry and Chemical Engineering of Harbin Institute of Technology (HIT), and State Key Laboratory of Urban Water Resource and Environment (HIT).

Authors' contributions YL: Conceptualization, Methodology, Formal analysis, Investigation, Visualization, Writing-Original Draft. HS: Formal analysis, Investigation, Validation, Visualization. YC: Formal analysis, Investigation. CY: Supervision. YF: Supervision. YY: Conceptualization, Writing - Review \& Editing. All authors read and approved the final manuscript.

Funding This work was supported by the National Key Research and Development Program of China [2017YFA0207201], the National Natural Science Foundation of China (Grant No. 2197020577). 
Availability of data and materials The datasets used or analyzed during the current study are available from the corresponding author on reasonable request.

Code availability Not applicable.

\section{Declarations}

Consent for publication Agreed to publish.

Conflict of interests The authors declare that they have no conflict of interests.

Ethics approval and consent to participate Not applicable.

Open Access This article is licensed under a Creative Commons Attribution 4.0 International License, which permits use, sharing, adaptation, distribution and reproduction in any medium or format, as long as you give appropriate credit to the original author(s) and the source, provide a link to the Creative Commons licence, and indicate if changes were made. The images or other third party material in this article are included in the article's Creative Commons licence, unless indicated otherwise in a credit line to the material. If material is not included in the article's Creative Commons licence and your intended use is not permitted by statutory regulation or exceeds the permitted use, you will need to obtain permission directly from the copyright holder. To view a copy of this licence, visit http://creativecommons.org/licenses/by/4.0/.

\section{References}

Ben Y, Hu M, Zhang X, Wu S, Wong MH, Wang M et al (2020) Efficient detection and assessment of human exposure to trace antibiotic residues in drinking water. Water Res 175:115699. https:// doi.org/10.1016/j.watres.2020.115699

Carvalho IT, Santos L (2016) Antibiotics in the aquatic environments: a review of the European scenario. Environ Int 94:736-757. https:// doi.org/10.1016/j.envint.2016.06.025

Chang HY, Yun HP, Oh GH, Chong RP (2003) Contribution of inorganic components in precursors to porosity evolution in biomassbased porous carbons. Carbon 41(10):2009-2012. https://doi.org/ 10.1016/S0008-6223(2003)00154-00154

Chen S, Zhang W, Li J, Yuan M, Zhang J, Xu F et al (2020) Ecotoxicological effects of sulfonamides and fluoroquinolones and their removal by a green alga (Chlorella vulgaris) and a cyanobacterium (Chrysosporum ovalisporum). Environ Poll 263:114554. https://doi.org/10.1016/j.envpol.2020.114554

Cheng B, Tian K, Zeng RJ, Jiang H (2017) Preparation of high performance supercapacitor material by fast pyrolysis of corn gluten meal waste. Sustain Energy Fuels 1:891-898. https://doi.org/10. 1039/c7se00029d

Cui J, Fu L, Tang B, Bin L, Li P, Huang S, Fu F (2020) Occurrence, ecotoxicological risks of sulfonamides and their acetylated metabolites in the typical wastewater treatment plants and receiving rivers at the Pearl River Delta. Sci Total Environ 709:136192. https://doi.org/10.1016/j.scitotenv.2019.136192

Danner MC, Robertson A, Behrends V, Reiss J (2019) Antibiotic pollution in surface fresh waters: occurrence and effects. Sci Total Environ 664(10):793-804. https://doi.org/10.1016/j.scitotenv. 2019.01.406
Dutta T, Kim T, Vellingiri K, Tsang DCW, Shonf JR, Kim K-H, Kumarg S (2019) Recycling and regeneration of carbonaceous and porous materials through thermal or solvent treatment. Chem Eng J 364:514-529. https://doi.org/10.1016/j.cej.2019.1001.1049

Elder FCT, Feil EJ, Snape J, Gaze WH, Kasprzyk-Hordern B (2020) The role of stereochemistry of antibiotic agents in the development of antibiotic resistance in the environment. Environ Int 139:105681. https://doi.org/10.1016/j.envint.2020.105681

Emma M (2006) Putting the carbon back: black is the new green. Nature 442(7103):624-626. https://doi.org/10.1038/442624a

Fei Y, Yong L, Sheng H, Jie M (2016) Adsorptive removal of antibiotics from aqueous solution using carbon materials. Chemosphere 153:365-385. https://doi.org/10.1016/j.chemosphere.2016.03.083

Fu Y, Shen Y, Zhang Z, Ge X, Chen M (2018) Activated bio-chars derived from rice husk via one- and two-step $\mathrm{KOH}$-catalyzed pyrolysis for phenol adsorption. Sci Total Environ 646:15671577. https://doi.org/10.1016/j.scitotenv.2018.07.423

Grenni P, Ancona V, Barra Caracciolo A (2017) Ecological effects of antibiotics on natural ecosystems: a review. Microchem J 136:2539. https://doi.org/10.1016/j.microc.2017.1002.1006

Han X, Liang C, Li T, Wang K, Huang H, Yang X (2013) Simultaneous removal of cadmium and sulfamethoxazole from aqueous solution by rice straw biochar. J Zhejiang Univ Sci B 14(7):640-649. https://doi.org/10.1631/jzus.B1200353

Han QF, Zhang XR, Xu XY, Wang XL, Yuan XZ, Ding ZJ et al (2020) Antibiotics in marine aquaculture farms surrounding Laizhou Bay, Bohai Sea: distribution characteristics considering various culture modes and organism species. Sci Total Environ 760:143863. https://doi.org/10.1016/j.scitotenv.2020.143863

Hayes MHB (2006) Biochar and biofuels for a brighter future. Nature 443(7108):144-144. https://doi.org/10.1038/443144c

Huang H, Niu Z, Shi R, Tang J, Fan Y (2020) Thermal oxidation activation of hydrochar for tetracycline adsorption: the role of oxygen concentration and temperature. Bioresour Technol 306:123096. https://doi.org/10.1016/j.biortech.2020.123096

Isidori M, Lavorgna M, Nardelli A, Pascarella L, Parrella A (2005) Toxic and genotoxic evaluation of six antibiotics on non-target organisms. Sci Total Environ 346(1-3):87-98. https://doi.org/10. 1016/j.scitotenv.2004.1011.1017

Jia M, Fang W, Bian Y, Xin J, Yang S, Kengara FO et al (2013) Effects of $\mathrm{pH}$ and metal ions on oxytetracycline sorption to maize-strawderived biochar. Bioresour Technol 136:87-93. https://doi.org/10. 1016/j.biortech.2013.1002.1098

Jiao Y, Dongyang W, M., Gong, T., Sun, M., \& Yang, T. (2021) A scientometric review of biochar preparation research from 2006 to 2019. Biochar 3:283-298. https://doi.org/10.1007/ s42773-021-00091-5

Jutkina J, Rutgersson C, Flach C-F, Larsson DGJ (2016) An assay for determining minimal concentrations of antibiotics that drive horizontal transfer of resistance. Sci Total Environ 548-549:131-138. https://doi.org/10.1016/j.scitotenv.2016.1001.1044

Li L, Guo C, Fan S, Lv J, Zhang Y, Xu Y, Xu J (2018) Dynamic transport of antibiotics and antibiotic resistance genes under different treatment processes in a typical pharmaceutical wastewater treatment plant. Environ Sci Pollut Res Int 25:30191-30198. https:// doi.org/10.31007/s11356-30018-32913-30192

Li Y, Xing B, Ding Y, Han X, Wang S (2020) A critical review of the production and advanced utilization of biochar via selective pyrolysis of lignocellulosic biomass. Bioresour Technol 312:123614. https://doi.org/10.1016/j.biortech.2020.123614

Lillo-Ródenas MA, Cazorla-Amorós D, Linares-Solano A (2003) Understanding chemical reactions between carbons and $\mathrm{NaOH}$ and KOH. Carbon 41:267-275. https://doi.org/10.1016/S00086223(1002)00279-00278

Ling Q, Zhou Z, Dai J, Ping M, Zhao H, He J, Yan Y (2016) Novel $\mathrm{N}$-doped hierarchically porous carbons derived from sustainable 
shrimp shell for high-performance removal of sulfamethazine and chloramphenicol. J Taiwan Inst Chem Eng 62:228-238. https:// doi.org/10.1016/j.jtice.2016.1002.1009

Muniandy L, Adam F, Mohamed AR, Ng E-P (2014) The synthesis and characterization of high purity mixed microporous/mesoporous activated carbon from rice husk using chemical activation with $\mathrm{NaOH}$ and KOH. Microporous Mesoporous Mater 197:316-323. https://doi.org/10.1016/j.micromeso.2014.1006.1020

Nakada N, Shinohara H, Murata A, Kiri K, Managaki S, Sato N, Takada H (2007) Removal of selected pharmaceuticals and personal care products (PPCPs) and endocrine-disrupting chemicals (EDCs) during sand filtration and ozonation at a municipal sewage treatment plant. Water Research 41(19):4373-4382. https://doi. org/10.1016/j.watres.2007.06.038

Ndirangu SM, Liu Y, Xu K, Song S (2019) Risk evaluation of pyrolyzed biochar from multiple wastes. J Chem 2019(4506314):1-28. https://doi.org/10.1155/2019/4506314

Ngigi AN, Ok YS, Thiele-Bruhn S (2019) Biochar-mediated sorption of antibiotics in pig manure. J Hazard Mater 364:663-670. https:// doi.org/10.1016/j.jhazmat.2018.1010.1045

Shi C, Hu L, Guo K, Li H, Zhai T (2017) Highly porous carbon with graphene nanoplatelet microstructure derived from biomass waste for high-performance supercapacitors in universal electrolyte. Adv Sustain Syst 1:1600011. https://doi.org/10.1002/adsu.201600011

Souza MJD, Nair S, Bharathi PAL, Chandramohan D (2006) Metal and antibiotic-resistance in psychrotrophic bacteria from Antarctic Marine waters. Ecotoxicology 15(4):379-384. https://doi.org/10. 1007/s10646-006-0068-2

Tang L, Yu J, Pang Y, Zeng G (2018) Sustainable efficient adsorbent: Alkali-acid modified magnetic biochar derived from sewage sludge for aqueous organic contaminant removal. Chem Eng J 336:160-169. https://doi.org/10.1016/j.cej.2017.1011.1048

Tomlinson TG, Boon AG, Trotman CNA (2010) Inhibition of nitrification in the activated sludge process of sewage disposal. J Appl Bacteriol 29(2):266-291. https://doi.org/10.1111/j.1365-2672. 1966.tb03477.x

Wang H, Wang N, Wang B, Zhao Q, Fang H, Fu C, Jiang Q (2016) Antibiotics in drinking water in shanghai and their contribution to antibiotic exposure of school children. Environ Sci Technol 50(5):2692-2699. https://doi.org/10.1021/acs.est.2695b05749

Wang B, Jiang YS, Li FY, Yang DY (2017) Preparation of biochar by simultaneous carbonization, magnetization and activation for norfloxacin removal in water. Bioresour Technol 233:159-165. https://doi.org/10.1016/j.biortech.2017.1002.1103
Wang B, Zhang W, Li H, Fu H, Qu X, Zhu D (2017) Micropore clogging by leachable pyrogenic organic carbon: a new perspective on sorption irreversibility and kinetics of hydrophobic organic contaminants to black carbon. Environ Pollut 220:1349-1358. https://doi.org/10.1016/j.envpol.2016.1310.1100

Wu CH (2007) Adsorption of reactive dye onto carbon nanotubes: equilibrium, kinetics and thermodynamics. J Hazard Mater 144(1):93100. https://doi.org/10.1016/j.jhazmat.2006.1009.1083

Wu P, Wang Z, Wang H, Bolan NS, Wang Y, Chen W (2020) Visualizing the emerging trends of biochar research and applications in 2019: a scientometric analysis and review. Biochar 2:135-150. https://doi.org/10.1007/s42773-020-00055-1

Yan L, Wang Z, Xie X, Zhu J, Li R, Qin T (2017) Removal of Norfloxacin from aqueous solution by clay-biochar composite prepared from potato stem and natural attapulgite. Coll Surf A Physicochem Eng Aspects 514:126-136. https://doi.org/10.1016/j.colsu rfa.2016.1011.1064

Yang H, Yan R, Chen H, Dong HL, Zheng C (2007) Characteristics of hemicellulose, cellulose and lignin pyrolysis. Fuel 86(12):17811788. https://doi.org/10.1016/j.fuel.2006.1712.1013

Yang X, Chen F, Meng F, Xie Y, Chen H, Young K et al (2013) Occurrence and fate of PPCPs and correlations with water quality parameters in urban riverine waters of the Pearl River Delta, South China. Environ Sci Pollut Res 20(8):5864-5875. https:// doi.org/10.1007/s11356-11013-11641-x

Yang H, Ye S, Zeng Z, Zeng G, Tan X, Xiao R et al (2020) Utilization of biochar for resource recovery from water: a review. Chem Eng J 397:125502. https://doi.org/10.1016/j.cej.2020.125502

Zhang G, Lu S, Wang Y, Liu X, Liu Y, Xu J et al (2020) Occurrence of antibiotics and antibiotic resistance genes and their correlations in lower Yangtze River China. ScienceDirect 257:113365. https:// doi.org/10.1016/j.envpol.2019.113365

Zhu X, Liu Y, Feng Q, Chao Z, Zhang S, Chen J (2014) Preparation of magnetic porous carbon from waste hydrochar by simultaneous activation and magnetization for tetracycline removal. Bioresour Technol 154:209-214. https://doi.org/10.1016/j.biortech.2013. 12.019

Zhu X, Li C, Li J, Xie B, Lü J, Li Y (2018) Thermal treatment of biochar in the air/nitrogen atmosphere for developed mesoporosity and enhanced adsorption to tetracycline. Bioresour Technol 263:475-482. https://doi.org/10.1016/j.biortech.2018.1005.1041

\section{Authors and Affiliations}

\section{Yinxue $\mathrm{Li}^{1} \cdot$ Hongru Shang ${ }^{1} \cdot$ Yongna Cao $^{1} \cdot$ Chunhui Yang $^{1,2} \cdot$ Yujie Feng $^{2} \cdot$ Yanling Yu $^{1}$}

1 School of Chemistry and Chemical Engineering, The 1st campus, Harbin Institute of Technology, No 92 Xidazhi Street, Nangang District, Harbin 150001, People's Republic of China
2 State Key Laboratory of Urban Water Resource and Environment, Harbin 150090, People's Republic of China 